
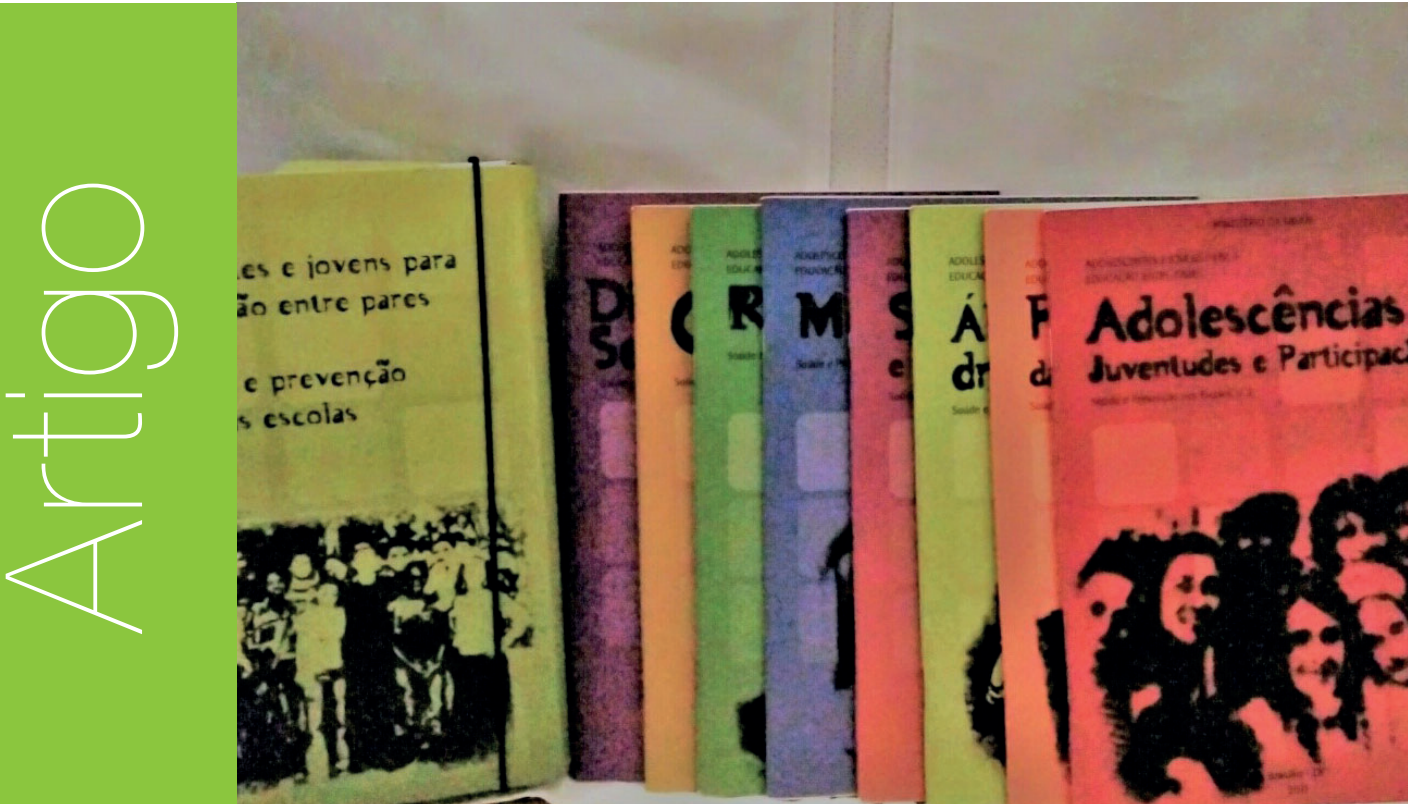

\title{
O projeto saúde e prevenção nas escolas em Quixadá: uma perspectiva da transdisciplinaridade e complexidade
}

\author{
Francisca Mara Raquel Silva Almeida ${ }^{1}-$ \\ mara.rakel.10@gmail.com \\ Cintia Paloma Lopes Lima² - cintiapalom@gmail.com \\ Cândida Maria Farias Câmara ${ }^{3}$ - \\ candidapsicologia@gmail.com
}

\section{RESUMO}

Este trabalho é fruto de uma experiência dos membros do Grupo de Estudo, Pesquisa e Extensão em Psicologia, Arte e Educação do Centro Universitário Católica de Quixadá. Possui como objetivo discutir a aplicação de oficinas do Projeto Saúde e Prevenção nas Escolas, a partir da obra de Edgar Morin. A metodologia consistiu em desenvolver duas oficinas do fascículo 2, oferecidas pelo projeto, em uma escola da rede pública, nas quais buscou-se despertar o protagonismo das crianças e dos adolescentes, apoiando-se em temáticas que abordam a realidade em que estão inseridos os participantes. Conclui-se, assim, que as oficinas contribuíram para o desenvolvimento psicossocial e educacional dos participantes.

\section{PALAVRAS-CHAVE}

Transdisciplinaridade. Complexidade. Educação do Futuro. Oficinas. Edgar Morin.

\footnotetext{
1 Graduanda em Psicologia pelo Centro Universitário Católica de Quixadá.

2 Graduanda em Psicologia pelo Centro Universitário Católica de Quixadá.

3 Psicóloga, Professora do Centro Universitário Católica de Quixadá e Orientadora do GEPAE.
} 


\section{ABSTRACT}

This work is the result of an experience of the members of the Group of Study, Research and Extension in Psychology, Art and Education of the Centro Universitário Católica de Quixadá. It has as objective to discuss the application of workshops of the Project Health and Prevention in Schools, from work of Edgar Morin. The methodology consisted of developing two workshops of the issue 2, offered by the project, in a public school, in which aimed at awakening the protagonism of children and adolescents, relying on themes that address the reality in which they are the participants. It was concluded that these workshops contributed to the psychosocial and educational development of the participants.

\section{KEYWORDS}

Transdisciplinarity. Complexity. Education of the Future. Offices. Edgar Morin.

\section{Introdução}

As transições da vida são essenciais para a formação psíquica, social e biológica de qualquer ser humano. A adolescência, sem dúvida, é uma das fases mais importantes e as questões inerentes a ela têm sido o foco de atenção de estudantes, profissionais, e também do Governo Federal. Todavia, sabe-se da precarização de políticas públicas que venham a beneficiar as crianças e adolescentes da rede pública de ensino que estão em formação (SILVA; LOPES, 2009).

Para tanto, o presente trabalho relata uma experiência dos estudantes do Grupo de Estudo, Pesquisa e Extensão em Psicologia Arte e Educação (GEPAE) do Centro Universitário Católica de Quixadá (UNICATÓLICA), em parceria com a Secretaria Municipal de Educação da cidade de Quixadá, que buscou a implantação do Projeto Saúde e Prevenção nas Escolas (SPE), enquanto uma extensão do Programa Saúde na Escola (PSE).

0 PSE é um programa do Governo Federal, que foi regulamentado pelo Ministério da Saúde e 0 Ministério da Educação, através do Decreto Presidencial n 6.286 de 5 de dezembro de 2007. Esse projeto visa ampliar as ações de saúde aos alunos que fazem parte da rede pública de ensino (BRASIL, 2011).

Já o SPE possibilita a intersetorialidade e, porque não dizer também, a transdisciplinaridade, já que esse projeto envolve uma série de trocas de conhecimentos, bem como a articulação e integração, buscando melhorias na qualidade de vida brasileira. Tem como foco capacitar jovens multiplicadores que possam repassar ações de promoção, prevenção e atenção à saúde, visando o melhor desenvolvimento de crianças e adolescentes que compõem a rede pública de ensino (BRASIL, 2011).

Em uma visão ampla, a saúde é um direito de todos, garantido na constituição de 1988 e que atualmente busca, incansavelmente, abranger a toda população brasileira, visando à promoção de qualidade de vida e de fácil acesso. Desse modo, é preciso que as ações em saúde se estendam para outros setores da sociedade, contribuindo assim para promover a reflexão e expansão dos conhecimentos acerca da prevenção de doenças. Para tanto, a escola pode se tornar uma aliada, visto que insere a comunidade, o educando e a família.

A educação também é um direito de todos, garantido na constituição de 1988, e em um elo com a saúde pode desenvolver um atendimento que potencializa a própria saúde. É no trabalho conjunto entre os setores da saúde e da educação que se observa a intersetorialidade desse projeto. A educação é essencial para o conhecimento e, consequentemente, para a formação psíquica de qualquer ser humano, acredita-se que a mesma é a formadora de opiniões, favorecendo constantemente ao desenvolvimento de seres conscientes e responsáveis por seus atos e escolhas.

Neste sentido, o elo entre educação e saúde propõe alcançar crianças e adolescentes que estão inseridos na rede pública de ensino, promover o conhecimento a respeito de prevenção para esse público que dificilmente apresenta-se ao serviço de saúde. Observa-se 
que 0 adolescente aprende mais com outro adolescente, 0 que confere ao PSE um excelente recurso de intervenção em saúde e em educação.

Confia-se que esse elo poderá ampliar os conhecimentos sobre educação em saúde dos jovens da rede pública de ensino da cidade de Quixadá, bem como promover a capacitação desses jovens para a reflexão e discussão de temas relevantes na atualidade.

Este trabalho conta como principal referência o pesquisador Edgar Morin e suas pesquisas sobre transdisciplinaridade, complexidade e a educação do futuro. Possui como objetivo geral discutir a aplicação de oficinas do Projeto Saúde e Prevenção nas Escolas, a partir da obra de Edgar Morin, em uma instituição educacional da rede municipal da cidade de Quixadá.

Ainda pretende-se, especificamente, identificar os principais conceitos acerca da complexidade e da transdisciplinaridade que perpassam o processo de implantação das oficinas do SPE e promover uma reflexão sobre o ensino dos conhecimentos atuais, visando o melhor desenvolvimento da multiplicação das oficinas.

\section{Metodolgia}

0 presente trabalho tem como metodologia a analise crítica e conceitual de duas oficinas do Projeto Saúde e Prevenção nas Escolas (SPE) tendo como base de discussão os fundamentos teórico e metodológico de Edgar Morin, o qual visa compreender os aspectos da complexidade, da transdisciplinaridade e da educação do futuro no atual modelo de ensino. Utilizando-se de uma discussão entre teoria e prática, esse estudo buscou implantar oficinas do Projeto Saúde e Prevenção nas Escolas se fundamentando nos conceitos citados. Para tal, se caracteriza enquanto pesquisa qualitativa, partindo da análise das falas dos indivíduos que compõem o grupo de jovens multiplicadores.

Figura 1: Marca do Projeto Saúde e Prevenção nas Escolas.

Fonte: http://www. saude.pa.gov. $\mathrm{br} / \mathrm{p}=1192$

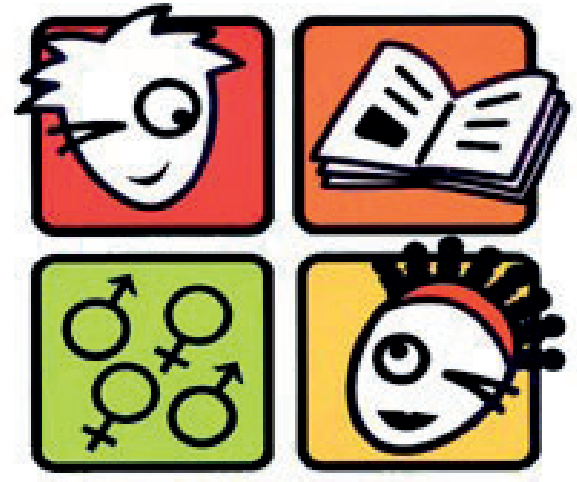

\section{SAúDE e PReVENGão NaS ESCoLAS}

Para a execução das oficinas foram realizados encontros a cada quinze dias, utilizandose de planejamento e encontros presenciais com 16 indivíduos, divididos entre crianças e adolescentes para a multiplicação das oficinas em sala de aula. As oficinas foram aplicadas para estudantes do fundamental 1 e 2 de uma escola da rede pública de Quixadá no período de fevereiro a dezembro de 2016. 

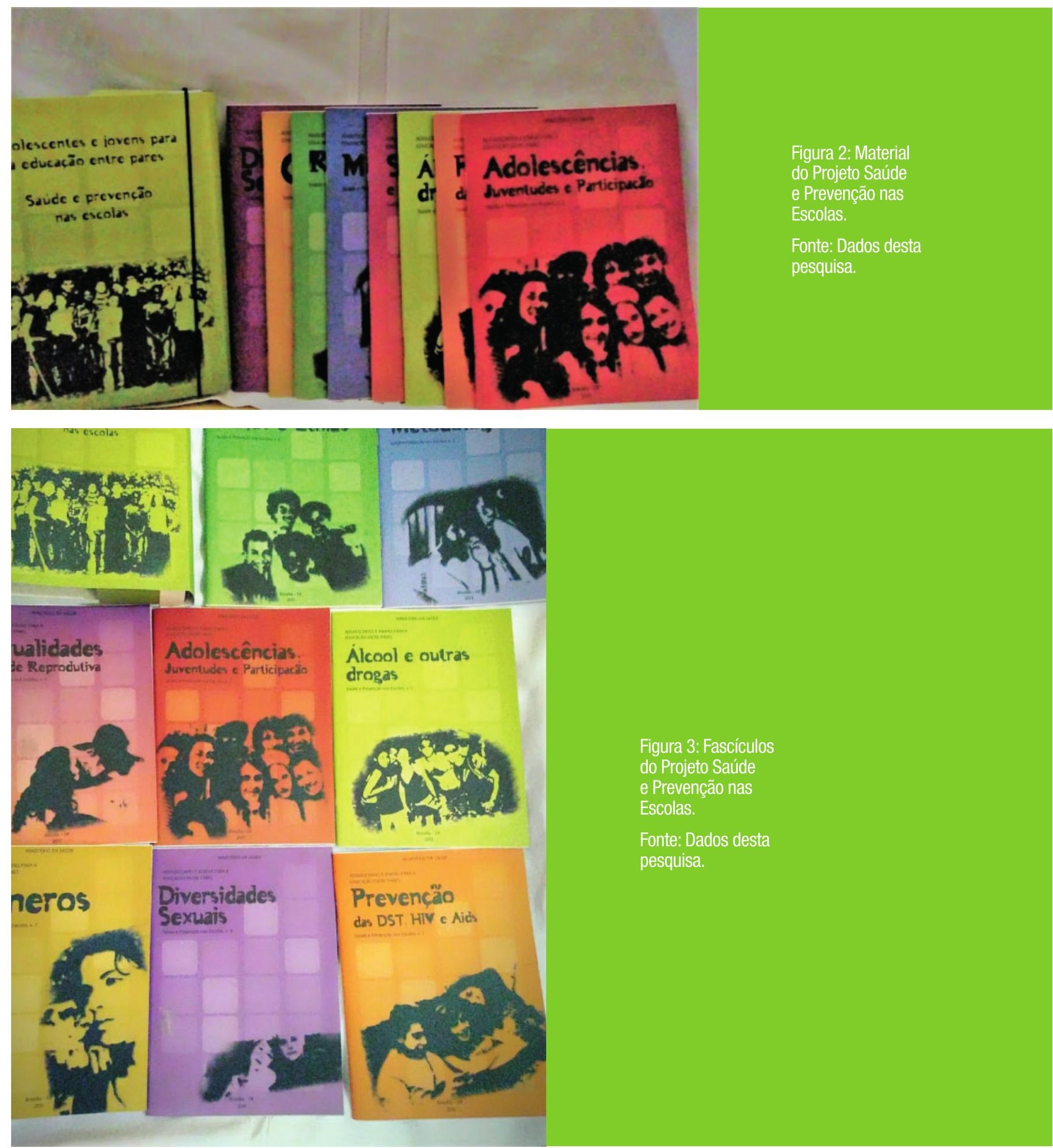

\section{Resultados e discussão}

\subsection{Apresentando uma experiência: A primeira oficina "A delícia de quem somos"}

A implantação do SPE, na rede pública da cidade de Quixadá, acontece desde setembro de 2015, porém, o presente trabalho vem relatar a experiência do ano de 2016, utilizando-se de um fascículo que contém 6 oficinas. Para este trabalho foram escolhidas duas oficinas, que pertencem ao fascículo volume 2, que tem como tema: Adolescências, juventudes e participação.

Para um melhor esclarecimento deste fascículo é importante salientar o objetivo da escolha do mesmo, pois o tema aborda assuntos próximos ao contexto dos adolescentes e que estimulam a 
integração e interação dos jovens a falar de forma mais geral sobre o que significa adolescência. Assim, entende-se que para a melhor aplicação dos demais fascículos seria interessante esses para 0 início, pois aborda a fase na qual os educandos estão inseridos, no caso, a adolescência. Estimulou-se uma melhor interação, compreensão dos fatos dessa juventude e por fim, colabora com a participação e a relevância do protagonismo juvenil.

Tendo em vista a abordagem de Edgar Morin e os estudos aprofundados sobre transdisciplinaridade, complexidade e os saberes necessários para educação de futuro, percebeu-se a importância dessas oficinas, uma vez que a primeira oficina desse fascículo vem tratar da "Delícia de ser quem somos". Segundo Morin (2003, p. 24):

Daí decorre a necessidade de reconhecer na educação do futuro um princípio de incerteza racional: a racionalidade corre risco constante, caso não mantenha vigilante autocrítica quanto a cair na ilusão racionalizadora. Isso significa que a verdadeira racionalidade não é apenas teórica, apenas crítica, mas também autocrítica.

Em um contexto mais complexo, pode-se entender a autocrítica como a oportunidade que possibilita a educação de futuro, visto que crianças e adolescentes pensantes são capazes de identificar suas incertezas, refazer suas ideias e se permitir enquanto ser pertencente à capacidade de errar (MORIN, 2003).

Portanto, a autocrítica, consequentemente, gera a racionalidade, ou seja, o poder pensar sobre 0 que somos, onde estamos inseridos, da atual realidade e ao mesmo tempo, criticando, entendendo e buscando a complexidade dos fatos. Em uma instância maior a autocrítica pode representar a compreensão que pode nos permitir uma total liberdade de pensar sem se reprimir (MORIN, 2003).

No mais, Morin (1998, p. 12) afirma que a complexidade nos convoca - e provoca - para uma mudança de pensamento, onde a compreensão do mundo se "autoproduz", conferindo também um sentido atual à ação.

Dessa forma, entende-se que os jovens precisam compreender as suas incertezas e de forma mais intrínseca, compreender o outro lado que recalcam, isto é, o lado onde estão as nossas incertezas, de ser complexo, de pensar diferente do outro e, por fim, afirma-se um ser errante. Todavia, deliciar-se por ser quem somos requer o questionar-se, o criticar-se, e buscar por respostas que estão no mais profundo do ser.

A presente oficina ainda vem abordar a transdisciplinaridade em um conceito de Edgar Morin, "o que poderíamos entender como o estudo do conhecimento de várias disciplinas, que interagem entre si e transcendem, contrapondo-se ao estudo especializado das partes e que, consequentemente, não contemplam o todo" (MORIN, 2003).

A transdisciplinaridade maximiza a aprendizagem ao trabalhar com imagens e conceitos que mobilizam, conjuntamente, as dimensões mentais, emocionais e corporais, tecendo relações tanto horizontais como verticais do conhecimento (SANTOS, 2008).

Vale ressaltar que esta oficina trata de diversas questões, onde se pode citar o questionarse sobre o meio que estamos inseridos, as precariedades, as diferenças entre os sexos, as expectativas da sociedade referente a um jovem, entre tantas outras questões. Isso nos faz perceber a necessidade de um contexto transdisciplinar, onde possa ser visto o todo, o completo.

Todavia, a atual proposta de ensino está cada vez mais especifica, precarizando a abertura de pensamentos do geral, para tanto se afirma que de acordo com 0 artigo 4 da Carta da Transdisciplinaridade:

0 ponto de sustentação da transdisciplinaridade reside na unificação semântica e operativa das acepções através e além das disciplinas. Ela pressupõe uma racionalidade aberta por um novo olhar, sobre a relatividade das noções de definição e objetividade. 0 formalismo excessivo, a rigidez das definições e 0 absolutismo da objetividade comportando a exclusão do sujeito levam ao empobrecimento (FREITAS et al, 1994, p.2). 
A escola tem um papel fundamental na modificação deste modelo de ensino, uma vez que a mesma possibilita a educação e a transformação de paradigmas. Para tanto, essas oficinas buscam provocar a reflexão na perspectiva de que esses jovens multiplicadores possam entender a relevância da não fragmentação do conhecimento.

Acredita-se que os multiplicadores podem entender, a partir do artigo 11 da Carta da Transdisciplinaridade, que a educação é autêntica não quando privilegia a abstração de conhecimento, mas quando se ensina a contextualizar, concretizar e globalizar esses conhecimentos. A educação transdisciplinar provoca a reavaliação do papel da intuição, da imaginação, da sensibilidade e do corpo para a transmissão de conhecimentos (FREITAS et al, 1994).

Porém, não se pode negar que a cada dia as especialidades se fecham em seu contexto e não permitem a integração com o global, um fato que as oficinas desse projeto tentam romper, já que lidamos com o psicológico, o cultural, o histórico, o emocional, e principalmente com o sujeito, que é a matéria mais complexa e transdisciplinar.

\subsection{A segunda oficina: "A escola que temos e a escola que queremos ter"}

Essa contraposição presente nas escolas nos fez escolher a segunda oficina para ser citada neste trabalho, "A escola que temos e a escola que queremos ter". Ela aborda 0 valor da escola na vida das crianças e adolescentes, provocando a discussão acerca do modelo de escola desejada, como poderia ser a organização para a construção de uma nova escola e a reflexão sobre os espaços concedidos e não concedidos.

Nessa oficina, os jovens multiplicadores puderam aplicá-la em uma sala de quarto ano do ensino fundamental I com 19 crianças. Esta foi a primeira experiência de aplicação desses jovens.

Foi observado que a sala de aula é o meio que desperta a complexidade. Uma vez que entendemos a necessidade de indagações sobre a realidade em que estes jovens estão inseridos, trazemos a reflexão de pertencer a uma espécie e a uma comunidade. Para seu crescimento intelectual e social deve-se buscar compreender as diversas disciplinas, rompendo a barreira do ser que entende a especificidade, mas não compreende e não interage com as demais.

Não se pode compreender a complexidade humana dissociada dos elementos que a formam, isto é, todo desenvolvimento que é verdadeiramente humano desenvolve um conjunto de autonomias individuais, a partir das participações comunitárias e do sentimento de pertença à espécie humana (MORIN, 2003).

Percebemos a importância dessa oficina quando os jovens aplicadores e a turma de 19 crianças participantes começaram a construir um modelo de escola ideal e, consequentemente, como deveria ser a educação, relatando a vontade de estudar outras disciplinas.

Acerca de educação, entende-se que a mesma deverá abordar os mais diversos contextos, que partam desde o social, histórico, cultural ao biológico, pois é na condição de educar que está a fórmula para desmistificar a complexidade humana.

Além desta oficina, os estudantes também usufruem de disciplinas, que dominam conteúdos que vão além do português e da matemática. 0 mais interessante é o desejo de participar e a relevância dada a esses conteúdos, que em nenhum momento foi menosprezado. Para tanto, firma-se a importância de oficinas, pois o ser humano necessita de conhecimentos que possam ir além do dito tradicional.

Santos e Hammerschmidt (2012) contribuem afirmando que o pensamento complexo tem por objetivos movimentar, conjugar e articular os diversos saberes compartimentados nas mais diversas áreas de conhecimento, mantendo a essência e especificidade de cada fenômeno.

Em um contexto escolar, a transdisciplinaridade se propõe a desconstruir a visão específica e cartesiana, em contrapartida visa um estudo do todo, o que contempla esta oficina, assim 
como as outras aplicadas nesta instituição. É importante enfatizar mais uma vez que nenhuma disciplina é superior à outra, uma vez que todas contribuem para a formação do ser.

Para tanto, Santos (2008) afirma que a transdisciplinaridade demanda uma atitude de democracia cognitiva, isto é, todos os saberes são relevantes, vencendo o prejulgamento ingressado pela hierarquização dos saberes. 0 autor ainda acrescenta:

0 conhecimento transdisciplinar associa-se à dinâmica da multiplicidade das dimensões da realidade e apoia-se no próprio conhecimento disciplinar. Isso quer dizer que a pesquisa transdisciplinar pressupõe a pesquisa disciplinar, no entanto, deve ser enfocada a partir da articulação de referências diversas. Desse modo, os conhecimentos disciplinares e transdisciplinares não se antagonizam, mas se complementam (SANTOS, 2008, p. 75).

Todavia, o atual modelo de ensino usado nas escolas não aborda essa associação, é o que atrofia cada vez mais o conhecimento de mundo das crianças e adolescentes, que precisam ter um conhecimento pertinente, capaz de compreender o que somos, onde estamos, de onde viemos, podendo relacioná-los e, por fim, interpretá-los.

Segundo Morin (2003), não se pode separar o ser humano do universo, mas sim, situá-lo nele. Os conhecimentos necessitam ser contextualizados para serem pertinentes, ou seja, os saberes precisam ser relacionados à realidade dos educandos.

Ainda em um contexto de ser humano, transdisciplinaridade e condição humana, destaca-se nesta oficina o objetivo em despertar outras aptidões, visto que as atividades realizadas envolviam a criação de desenhos, frases, versos, e o que pudesse descrever a escola que queremos. Pinho e colaboradores (2015) ressaltam que 0 trabalho coletivo exerce grande influência no desenvolvimento humano, uma vez que atua considerando 0 caráter subjetivo e 0 coletivo dos sujeitos.

Por fim, destacamos a relevância desta oficina para com 0 acréscimo de conhecimentos, interagindo-os e propondo uma visão ampla, visando contemplar a reflexão da realidade em que esses jovens estão inseridos. Ainda, destaca-se que as obras de Edgar Morin contribuíram diretamente para a aplicação destas oficinas, o que ressalta que estas obras foram para além de uma discussão científica, uma vez que a inteligência está na busca pela compreensão de meios que venham para acrescentar, para somar.

\section{Considerações finais}

Este trabalho se propôs, de forma breve, a apresentar uma experiência de implantação de jovens multiplicadores do Projeto Saúde e Prevenção nas Escolas com base na discussão da obra de Edgar Morin.

Não se limitando apenas à teoria, o presente trabalho relata uma experiência, que em suma, baseouse pela busca de saberes atuais da educação do futuro. Buscou-se, também, compreender o novo modelo de ensino, que se propõe a um novo ensino, que está distante do comum e que precisa a cada dia ser mais estudado, de forma transdisciplinar.

Pode-se chegar, assim, a algumas questões: não basta somente investir na reforma das instituições de ensino, não adianta apenas investir em um modelo de ensino que fuja da nossa realidade, ou seja, a reforma deve iniciar nas mentes das crianças e se estender aos adolescentes.

Todavia, ainda percebe-se a necessidade de políticas públicas educacionais que venham atender a realidade dessas crianças e adolescentes, que visem um estudo que provoque a discussão e que, assim, as instituições formem seres de opiniões próprias, autocríticos e conhecedores dos mais diversos saberes.

Ainda, firma-se novamente a necessidade de um ensino mais abrangente, que transpasse as disciplinas. Em outras palavras, que contextualize as disciplinas, utilizando-se do cultural e do social, que busque o complexo do ser e que desmistifique esse complexo. Eis, portanto, uma perspectiva que também nos leva a procurar um elo complexo entre indivíduo e espécie, indivíduo e sociedade. 
Uma conclusão bem perceptível, uma vez que a complexidade do ser é tratada como invisível nas instituições de ensino.

Diante das considerações traçadas, entende-se que as oficinas apresentadas nesse trabalho acrescentaram, de forma significativa, novos conhecimentos e valores para as crianças e adolescentes participantes. Entende-se, ainda, a necessidade na continuidade desse trabalho, pois é perceptível que essa política pública educacional poderá esclarecer dúvidas acerca da educação de futuro.

\section{Referências}

BRASIL. Passo a passo PSE programa saúde na escola: tecendo caminhos da intersetorialidade. Brasilia: Ministério da Saúde, 2011. Disponível em: <http://189.28.128.100/dab/docs/legislacao/ passo_a_passo_pse.pdf>. Acesso em: 13 fev. 2017.

FREITAS, L.; NICOLESCU, B.; MORIN, E. (org). Carta da Transdisciplinaridade: Primeiro Congresso Mundial de transdisciplinaridade. Convento da Arrábida, Portugal, 2 a 6 de novembro, 1994.

MORIN, Edgar. A cabeça bem-feita: repensar a reforma, reformar o pensamento. 8 ed. Rio de Janeiro: Bertrand Brasil, 2003. 128 p.

Ensayos THOT: Complexidade e Liberdade. Revista da Associação Palas Athena São Paulo, edição 67, p. 12-19, 1998.

PINHO, M. J. et al. (org). Complexidade, interdisciplinaridade e transdisciplinaridade na educação superior. Goiânia: Editora Espaço Acadêmico. 2015. 188 p.

SANTOS, A. Complexidade e transdisciplinaridade em educação: cinco princípios para resgatar o elo perdido. Revista Brasileira de Educação, v. 13, n. 37, jan./abr. 2008.

SANTOS, S.S.C.; HAMMERSCHMIDT, K.S.A de A. A complexidade e a religação de saberes interdisciplinares: contribuição do pensamento de Edgar Morin. Revista Brasileira de Enfermagem, Brasilia, v.65, n.4, p. 561-565, 2012.

SILVA, C. R; LOPES, R. E. Adolescência e juventude: entre conceitos e políticas públicas. Cadernos de Terapia Ocupacional da UFSCar, São Carlos, v. 17, n. 2, p. 87-106, jul./dez. 2009. 